\title{
ASPEK HUMOR DALAM AKUN INSTAGRAM @NUGARISLUCU DAN IMPLIKASINYA DALAM PEMBELAJARAN BAHASA INDONESIA DI SMA
}

\author{
Ayuningtias Srikandini \\ Pendidikan Bahasa dan Sastra Indonesia, Fakultas Keguruan dan Ilmu Pendidikan, Universitas \\ Pancasakti Tegal, Email: inikandin14yu@gmail.com

\section{Burhan Eko Putwanto} \\ Pendidikan Bahasa dan Sastra Indonesia, Fakultas Keguruan dan Ilmu Pendidikan, Universitas \\ Pancasakti Tegal, Email: burhan.ekopurwanto@gmail.com
}

\section{Agus Riyanto}

Pendidikan Bahasa dan Sastra Indonesia, Fakultas Keguruan dan Ilmu Pendidikan, Universitas Pancasakti Tegal, Email: alkhalifiriyanto@gmail.com.

\begin{abstract}
Abstrak
Perkembangan teknologi internet yang terus mengalir dan tidak terbendung sebagai inovasi dalam dakwah atau menyebarkan informasi yang mengandung nilai-nilai agama dapat dikatakan efektif. Penyampaian dalam proses dakwah itu terdapat berbagai macam teknik yang dapat dilakukan oleh penceramah agar pesan yang dibawakan dapat tersampaikan dengan baik oleh penceramah, salah satunya adalah humor pada postingan instagram. Penelitian ini bertujuan untuk mengetahui apa saja aspek humor pada postingan akun instagram @nugarislucu dan implikasinya dalam pembelajaran bahasa Indonesia di SMA. Penelitian ini menggunakan pendekatan kualitatif, sumber data penelitian yaitu akun instagram @ nugarislurus. Wujud data yaitu penggalan wacana dan kalimat Teknik pengumpulan data yaitu teknik simak dan teknik catat. Data yang diperoleh dianalisis menggunakan metode deskriptif. Hasil penelitian diperoleh 36 data yang mengandung aspek humor dalam postingan akun Instagram @ nugarislucu bulan Maret dan Mei, antara lain affiliative humor sebanyak 6 postingan (16,67\%), self-enhancing humor sebanyak 7 postingan (19,44\%), aggresive humor sebanyak 17 postingan (47, 22\%) dan self-defeating humor sebanyak 6 postingan $(16,67 \%)$.
\end{abstract}

Kata kunci: humor, instagram dan pembalajaran bahasa.

\begin{abstract}
The development of internet technology that continues to flow and is unstoppable as innovation in propaganda or disseminating information that contains religious values can be said to be effective. Submission of the preaching process and even then there are various kinds of techniques that can be carried out by the lecturer so that the message delivered can be conveyed well by the audience, one of which is humor on Instagram posts. This study aims to determine what aspects of humor on the Instagram account post @ nugarislucu and its implications in learning Indonesian in high school. This study uses a qualitative approach, the source of research data is the Instagram account @ugarislurus. The data form is a fragment of discourse and sentences Data collection techniques are listening techniques and note taking techniques. The data obtained were analyzed using descriptive methods. The results obtained 36 data containing aspects of humor in Instagram @ nugarislucu Instagram posts in March and May, including 6 affiliative humor posts (16.67\%), selfenhancing humor as many as 7 posts $(19.44 \%)$, aggressive humor as many as 17 posts $(47,22 \%)$ and self-defeating humor as many as 6 posts $(16.67 \%)$.
\end{abstract}

Keywords: humor, instagram and language learning. 


\section{PENDAHULUAN}

Kehadiran media baru menjadikan informasi sebagai sesuatu yang mudah dicari dan terbuka, salah satunya yaitu melalui instagram. Instagram sebagai aplikasi jejaring sosial yang dikhususkan untuk berbagi foto, memiliki ciri menarik yakni ada batas foto ke bentuk persegi, mirip dengan gambar kodak instamatic dan polaroid, yang sangat berbeda dengan rasio aspek 16:9 sekarang, biasanya digunakan oleh kamera ponsel.

Perkembangan teknologi dapat membawa pengaruh baik dan buruk, khususnya bagi remaja. Memanfaatkan perkembangan teknologi internet yang terus mengalir dan tidak terbendung sebagai inovasi dalam dakwah atau menyebarkan informasi yang mengandung nilai-nilai agama dapat dikatakan efektif. Dakwah dalam pelaksanaannya adalah mengajak pada hal yang baik dan mencegah kemungkaran, dalam penyampaian proses dakwah itupun terdapat berbagai macam teknik yang dapat dilakukan oleh penceramah agar pesan yang dibawakan dapat tersampaikan dengan baik oleh penceramah, salah satunya adalah humor.

Humor dalam dakwah mempunyai banyak fungsi diantaranya adalah sebagai hiburan, sarana mengkritik atau mengejek, searana untuk menyampaikan atau menjelaskan sesuatu agar lebih populer atau menarik. Namun demikian, selain berfungsi sebagai hiburan, sarana mengkritik atau mengejek, sarana untuk menyampaikan atau menjelaskan sesuatu agar lebih populer atau menarik, humor dalam dakwah juga bisa menjadi masalah diantaranya adalah kualitas konten humor yang disisipkan, porsi humornya melebihi porsi materi tablignya, banyak bermuncul para pelawak yang beralih profesi menjadi mubaligh (Ridwan, 2010:3).

Di era saat ini, humor dalam dakwah tidak hanya dilakukan melalui offline tetapi juga bisa dilakukan melalui online, di antaranya melalui instagram atau youtube. Salah satu akun instagram yang dikenal dalam menyampaikan pesan dakwah dengan memberikan unsur humor yang jenaka adalah@nugarislucu. Akun ini dikenal sebagai pendakwah komedi yang selalu memberikan sentuhan humor dalam dakwahnya.

Akun@nugarislucu mempunyai 1654 postingan dan 579.000 followers. Konten kata-kata yang dibagikan akun @ nugarislucu berupa pesan motivasi yang dikemas dengan bentuk foto dengan latar belakang yang menarik agar postingan tersebut menarik di baca masyarakat. Konten yang dibagikan umumnya mengandung katakata pelesetan, kata-kata yang mengundang tawa, menghibur, namun juga ada yang menggunakan kata-kata yang bernada mengejek.

Namun pada kenyataannya banyak remaja atau peserta didik yang membacara postingan-postingan dalam instagram, umumnya tidak mengetahui aspek humor 
dari bahasa yang disampaikan pada postingan tersebut. Pada intinya bahasa adalah tanda dan simbol yang mewakili sesuatu yang diungkapkan, baik lisan maupun tulisan (Swarniti \& Yuniari, 2019). Padahal penggunaan bahasa humor pada suatu wacana mempunyai tujuan tertentu yang ingin disampaikan. Pembelajaran bahasa Indonesia di sekolah sangat terbatas, sehingga perlu analisis bahasa yang lengkap, salah satunya yaitu pada postingan instagram. Melihat fenomena dan pentingnya pemahaman bahasa pada media sosial, pembelajaran bahasa Indonesia di sekolah dapat dijadikan sebagai ajang belajar tentang pentingnya pemahaman bahasa pada suatu wacana.

Agar tidak menyimpang dari judul dan tema yang telah ditentukan, maka penulis hanya membatasi permasalahan yang berkaitan dengan aspek humor dalam akun instagram@nugarislucu dan implikasinya dalam pembelajaran bahasa Indonesia di SMA. Berdasarkan latar belakang masalah di atas, dapat diidentifikasikan masalahmasalah dalam penelitian ini antar lain: 1) Humor dalam dakwah mempunyai banyak fungsi diantaranya adalah sebagai hiburan, sarana mengkritik atau mengejek, sarana untuk menyampaikan, 2) Humor dalam dakwah bisa menjadi masalah, yaitu kualitas konten humor yang disisipkan, porsi humornya melebihi porsi materi tablignya, 3) Pembelajaran bahasa Indonesia di sekolah sangat terbatas, analisis bahasa kurang lengkap karena hanya mempelajari materi- materi yang ada dalam buku, dan Analisis bahasa pada instagram dapat diimplikasikan bahan pembelajaran dalam proses belajar di SMA. Tujuan penelitian merupakan apa saja yang ingin dicapai dari penelitian ini yaitu: untuk mendeskripsi aspek humor pada postingan akun instagram @nugarislucu. Dan untuk mendeskripsi implikasi aspek humor pada postingan instagram @ nugarislucu dalam pembelajaran bahasa Indonesia di SMA.

\section{METODE}

Penelitian ini merupakan penelitian kualitatif (Santika, 2017). Desain yang digunakan dalam penelitian ini adalah metode deskriptif, dirancang untuk mengumpulkan informasi tentang keadaan nyata sekarang (sementara) berlangsung. Pendekatan ini digunakan untuk memberikan hasil penelitian yang berupa mendeskripsikan dan menganalisis aspek humor dalam akun instagram @ nugarislucu.

Objek penelitian ini adalah tindak tutur performatif. Data berupa wacana postingan instagram. Sumber data penelitian yaitu akun instagram@nugarislurus. Akun ini sangat menarik untuk diteliti karena akun @ nugarislucu mempunyai 1654 postingan dan 579.000 followers. Konten kata-kata yang dibagikan berupa pesan motivasi dikemas dengan bentuk tulisan dengan latar belakang sehingga menarik di baca. Konten umumnya mengandung pelesetan, mengundang tawa, menghibur, namun juga 
ada yang menggunakan kata-kata yang bernada mengejek.

Data dalam penelitian ini yaitu data mentah yang dikumpulkan penulis dan mengandung aspek humor dalam postingan. Adapun wujud data dalam penelitian ini berupa penggalan wacana dan kalimat yang terdapat dalam postingan-postingan akun @ nugarislucu. Teknik yang digunakan peneliti dalam pengumpulan data yaitu teknik simak dan teknik catat. Identifikasi data dalam penelitian ini adalah teknik trianggulasi data primer.

Teknik analisis data dalam penelitian ini menggunakan metode deskriptif. Menurut Best dalam Darmadi (2011:145) penelitian deskriptif merupakan jenis penelitian yang berusaha menggambarkan dan menginterpretasi objek sesuai dengan apa adanya. Penelitian ini penulis mendeskripsikan aspek dan fungsi bahasa humor dalam akun instagram @nugarislucu dan implikasinya dalam pembelajaran bahasa Indonesia di SMA.

\section{HASIL DAN PEMBAHASAN}

a. Aspek Humor pada Postingan Akun Instagram @nugarislucu

Berdasarkan hasil penelitian di atas, dapat diketahui dalam postingan akun Instagram@nugarislucu bulan Maret dan Mei terdapat 36 data yang mengandung aspek humor. Berikut rincian aspek humor yang ditemukan penulis.

Tabel 1. Klasifikasi Data Aspek Humor Postingan Akun Instagram @nugarislucu

\begin{tabular}{|c|c|c|c|c|}
\hline No & Aspek Humor & Jml & $\%$ & Data Postingan \\
\hline 1. & $\begin{array}{l}\text { Affiliative } \\
\text { humor }\end{array}$ & 6 & $16,67 \%$ & $02,03,08,12,18,28$ \\
\hline 2. & $\begin{array}{l}\text { Self-enhancing } \\
\text { humor }\end{array}$ & 7 & $19,44 \%$ & $01,05,14,15,17,19,20$ \\
\hline 3. & $\begin{array}{l}\text { Aggresive } \\
\text { humor }\end{array}$ & 17 & $47,22 \%$ & $\begin{array}{c}04,06,07,09,10,11,12,16,22,25,26,27,29,30, \\
31,33,36\end{array}$ \\
\hline 4. & $\begin{array}{l}\text { Self-defeating } \\
\text { humor }\end{array}$ & 6 & $16,67 \%$ & $21,23,24,32,34,36$ \\
\hline & Jumlah & 36 & $100 \%$ & \\
\hline
\end{tabular}

Berdasarkan tabel di atas, diperoleh 36 data yang mengandung aspek humor dalam postingan akun Instagram @ nugarislucu bulan Maret dan Mei, antara lain affiliative humor sebanyak 6 postingan $(16,67 \%)$, selfenhancing humor sebanyak 7 postingan (19,44\%), aggresive humor sebanyak 17 postingan $(47,22 \%)$ dan self-defeating humor sebanyak 6 postingan (16,67\%). Halhal menimbulkan humor pada postingan akun Instagram @nugarislucu meliputi: adanya sesuatu yang rendah atau lebih jelek, adanya penyimpangan dari sesuatu yang diharapkan, dan keinginan untuk 
membebaskan diri dari ketegangan atau tekanan psikis. Akun Instagram @ nugarislucu secara umum atau paling banyak mengandung aspek humor affiliative humor sebagai sarana mengkritik dengan menampilkan adanya sesuatu yang rendah atau lebih jelek.

\section{b. Implikasi Aspek Humor pada

Postingan Akun Instagram \\ @nugarislucu dalam Pembelajaran}

\section{Bahasa Indonesia di SMA}

Pembelajaran bahasa Indonesia diarahkan untuk meningkatkan kemampuan peserta didik untuk berkomunikasi dalam bahasa Indonesia dengan baik dan benar, baik secara lisan maupun tulis, serta menumbuhkan apresiasi terhadap hasil karya kesastraan manusia Indonesia. Dengan pembelajaran bahasa Indonesia, peserta didik dapat menguasai pengetahuan, keterampilan berbahasa, dan sikap positif terhadap bahasa dan sastra Indonesia. Hal tersebut merupakan dasar bagi peserta didik untuk memahami dan merespons situasi lokal, regional, nasional, dan global.

Peserta didik dapat mengembangkan potensinya sesuai dengan kemampuan, kebutuhan, dan minatnya, serta dapat menumbuhkan penghargaan terhadap hasil karya kesastraan dan hasil intelektual bangsa sendiri. Pembelajaran menulis di SMA bertujuan agar peserta didik memiliki kemampuan berkomunikasi secara efektif dan efisien sesuai dengan etika yang berlaku, baik secara lisan maupun tulis. Pembelajaran menulis di SMA semester XII dengan materi pokok "Berbagai Informasi dan Artikel". Standar Kompetensi (SK): Memahami informasi dari opini dalam bentuk artikel. Kompetensi Dasar (KD): 4.10 Menyusun opini dalam bentuk artikel. Indikator pencapaian kompetensi diharapkan peserta didik mampu mengkritisi masalah, fakta, opini, dan aspek kebahasaan dalam artikel.

Hasil penelitian ini mempunyai implikasi positif terhadap pembelajaran bahasa di SMA dan dapat dimanfaatkan oleh guru bahasa Indonesia sebagai bahan kajian dalam pembelajaran menulis aspek humor pada postingan akun instagram @ nugarislucu dapat diimplikasikan pada pembelajaran Teks Artikel dengan tujuan peserta didik dapat:

a. Mengidentifikasi masalah, fakta dan opini dari sebuah artikel yang dibaca.

b. Memahami kerangka penyusunan artikel.

c. Memahami prosedur penyusunan sebuah opini.

d. Mengkritisi masalah, fakta, opini, dan aspek kebahasaan dalam artikel.

e. Menulis opini dalam bentuk artikel dengan memerhatikan unsur artikel.

\section{PENUTUP}

Akun@instagram @nugarislucu, mengingatkan untuk selalu ibadah dan menyebarkan kedamaian. Tapi di sisi lain, kamu juga pasti bakalan terhibur dengan postingan dan quote-quotenya yang kocak. Hasil penelitian diperoleh 36 data yang 
mengandung aspek humor dalam postingan akunInstagram@nugarislucu bulan Maret dan Mei, antara lain affiliative humor sebanyak 6 postingan $(16,67 \%)$, selfenhancing humor sebanyak 7 postingan (19,44\%), aggresive humor sebanyak 17 postingan $(47,22 \%)$ dan self-defeating humor sebanyak 6 postingan $(16,67 \%)$. Berdasarkan hasil penelitian dan pembahasan dapat disimpulkan bahwa postingan akun instagram @nugarislucu terkait dengan aspek humor paling banyak mengandung aspek aggressive humor yaitu postingan yang berupa sindiran, ejekan atau cemoohan untuk menyindir.

Implikasi aspek humor postingan akun instagram@nugarislucu dapat diterapkan pada KD 4.10 Menyusun opini dalam bentuk artikel dengan indikator pencapaian kompetensi: peserta didik mampu mengkritisi masalah, fakta, opini, dan aspek kebahasaan sehingga peserta dapat Menulis opini dalam bentuk artikel dengan memerhatikan unsur artikel.

\section{Ucapan Terima Kasih}

Ucapan terima kasih kusampaikan kepada semua yang telah membantu sehingga karya ilmiah ini bisa terselesaikan. Pada kesempatan ini ucapan terima kasih kami sampaikan kepada"

a. Kedua orang tuaku yang aku cintai Alm. Bapak Tamudi dan Ibu Hasila.

b. Kakak dan adikku yang tersayang, $\mathrm{Ni}$ Imas Narendri dan Ifalah Dhiaulhaq. c. Sahabat seperjuanganku Gita Tri Lestari, Siti Nurjanah, Agustya Dyah N, Zulfatun Maghfiroh, Egi Ristiani, Rizkianti Shinta Putri, dan Desi Sinta, yang selalu memberi semangat dan dukungan serta canda tawa selama masa perkuliahan, sahabat-sahabat seperjuanganku.

d. Untuk seseorang yang spesial, terima kasih banyak untuk waktu, nasihatnasihatnya selama mengenal saya.

e. Semua pihak yang tidak dapat penulis sebutkan satu per satu yang telah membantu dalam penyelesaikan karya ilmiah ini.

\section{REFERENSI}

\section{Buku}

Abdullah, Asep Abbas. 2012. Humor Ulama, Surabaya: IAIN Sunan Ampel Press.

Alwi, Hasan. 2008. Kamus Besar Bahasa Indonesia. Jakarta: Balai Pustaka.

Amanda, Dewi. 2010. Implikatur Tindak Tutur Pada Humor Abang Jampang di Harian SIP. Jurnal Tata Bahasa

Atmoko, Bambang Dwi. 2012. Instagram Handbook Tips Fotografi Ponsel. Jakarta: Media Kita.

Chaer, Abdul. 2011. Tata Bahasa Praktis Bahasa Indonesia. Jakarta: Rineka Cipta.

Ghazali, Miliza. 2016. Buat Duit Dengan Facebook dan Instagram:Panduan Menjana Pendapatan dengan Facebook dan Instagram. Malaysia: Publishing House.

Iskandar. 2009. Metodologi Penelitian Kualitatif. Jakarta: Gaung Persada.

Moleong, Lexy J. 2000. Metodologi Penelitian Kualitatif. Bandung: Remaja Rosdakarya. 
Nasrullah, Rulli. 2016. Media Sosial: Perspektif Komunikasi, Budaya, dan Sosioteknologi. Bandung: Remaja Rosdakarya.

Rohmadi, Muhammad. 2010. Analisis Wacana Pragmatik. Surakarta: Yuma Pustaka.

Sagala, Syaiful. 2005. Konsep dan Makna Pembelajaran: untuk Membutuhkan Memecahkan Problemetika Belajar dan Mengajar. Bandung: Alfabeta,

Salbino, Sherief. 2014. Buku Pintar Gadget Android Untuk Pemula. Jakarta: Kunci Komunikasi.

Sawedi, Ikta. 2014. Humor dalam Bahasa Banggai. Skripsi tidak diterbitkan. Gorontalo: Universitas Negeri Gorontalo.

Santika, I Gusti Ngurah. 2017. Kepala Sekolah Dalam Konsep Kepemimpinan Pendidikan: Suatu Kajian Teoritis. Widya Accarya. 7 (1).

Santika, I Gusti Ngurah. 2018. Strategi Meningkatkan Kualitas SDM Masyarakat Desa Padangsambian Kaja Melalui Pendidikan Karakter Berbasiskan Kepedulian Lingkungan Untuk Membebaskannya Dari Bencana Banjir. Widya Accarya. 9 (2).

Solchan, T.W, dkk. 2014. Pendidikan Bahasa Indonesia di SD. Banten: UT.

Wiyanto, Asul. 2009. Terampil Menulis Paragraf. Jakarta: Grasindo.

Yuni, Putri. 2014. Teori-teori Humor. Padang: Universitas Negeri Padang.

Jurnal

Hidayah, Asri M. Nur. 2012. Wacana Humor Tertulis Dalam Bahasa Indonesia: Suatu Wacana Rekreatif. Jurnal Saweri Gading, Vol. 18, No. 1 (April 2012).

Listiyorini, Ari. 2017. Wacana Humor dalam Meme di Media Online sebagai Potret Kehidupan Sebagian Masyarakat Indonesia. LITERA, Vol. 16, No. 1 (April 2017)
Swarniti, N. W., \& Yuniari, N. M. (2019). Keberadaan Leksikon Pohon Langka di Denpasar: Studi Ekolinguistik. Seminar Nasional INOBALI 2019 Inovasi Baru Dalam Penelitian Sains, Teknologi Dan Humaniora, 405-411. https://eproceeding.undwi.ac.id/index. php/inobali/article/view/180

Wulandari, Rini; Saddhono, Kundharu; \& Rohmadi, Muhammad. 2014. Analisis Buku Humor Politik Pak Presiden, Buatlah Rakyat Stres Karya Edy Sumartono: Kajian Pragmatik dan Nilai-Nilai Pendidikan. BASASTRA Jurnal Penelitian Bahasa, Sastra Indonesia dan Pengajarannya, Vol. 2 No. 3 (Agustus 2014) ISSN I23026405.

Wijayanti, Asri. 2018. Homonimi dan Polisemi pada Unggahan Jenaka di Instagram. Transformatika: Jurnal Bahasa, Sastra, dan Pengajarannya, Vol. 2, No. 2, (September 2018), pp. 88-101, P-ISSN: 2549-5941, E-ISSN: 2549-6271.

Ridwan, Aang. 2010. Humor Dalam Tablig Sisipan Yang Sarat Estetika. Bandung: Jurnal UIN Sunan Gunung Djati, Vol. 4 No. 15, 2010.

\section{Artikel/Modul/Diktat}

Palupi, Dian. 2014. Bentuk dan Fungsi Bahasa Humor dalam Serial Drama Komedi Ekstra Francais Karya Whitney Barros. Jural Tata Bahasa

\section{Website}

http://.id.wikipedia.org./wiki/instagram

https://teknologi.bisnis.com/read/20190629/ 84/939306/daftar-penggunainstagram-terbanyak-di-duniaindonesia-di-urutan-berapa. 